\title{
High Anionic Conductive Form of PbxSn2-xF4
}

\section{$\operatorname{AUTHOR}(S)$ :}

Murakami, Miwa; Morita, Yoshiyuki; Yonemura, Masao; Shimoda, Keiji; Mori, Masahiro; Koyama, Yukinori; Kawaguchi, Tomoya; ... Kamiyama, Takashi; Uchimoto, Yoshiharu; Ogumi, Zempachi

\section{CITATION:}

Murakami, Miwa ...[et al]. High Anionic Conductive Form of PbxSn2-xF4. Chemistry of Materials 2019, 31(18): 7704-7710

\section{ISSUE DATE:}

2019-09-24

URL:

http://hdl.handle.net/2433/254344

\section{RIGHT:}

This document is the Accepted Manuscript version of a Published Work that appeared in final form in Chemistry of Materials, copyright (c) American Chemical Society after peer review and technical editing by the publisher. To access the final edited and published work see https://doi.org/10.1021/acs.chemmater.9b02623.; This is not the published version. Please cite only the published version.; この論文は出版社版でありません。引用の際には出版社版をご確認ご 利用ください。 


\section{High Anionic Conductive Form of $\mathrm{Pb}_{x} \mathrm{Sn}_{2-\mathrm{x}} \mathrm{F}_{4}$}

Miwa Murakami ${ }^{\dagger},{ }^{*}$, Yoshiyuki Morita ${ }^{\dagger}$, Masao Yonemura ${ }^{\ddagger}$, Keiji Shimoda ${ }^{\dagger}$, Masahiro Mori $^{\dagger}$, Yukinori Koyama ${ }^{\dagger}$, Tomoya Kawaguchi ${ }^{\dagger}$, Katsutoshi Fukuda ${ }^{\dagger}$, Yoshihisa Ishikawa $^{\ddagger}$, Takashi Kamiyama ${ }^{\ddagger}$, Yoshiharu Uchimoto ${ }^{\S}$, and Zempachi Ogumi ${ }^{\dagger}$

${ }^{\dagger}$ Office of Society-Academia Collaboration for Innovation, Kyoto University, Uji, Kyoto, 611-0011, Japan.

¥High Energy Accelerator Research Organization, Tokai-mura, Naka-gun, Ibaraki 319-1106, Japan

$\S$ Graduate School of Human and Environmental Studies, Kyoto University, Kyoto, 606-8501, Japan.

*email m-murakami@saci.kyoto-u.ac.jp

Gokasho, Uji, Kyoto 611-0011, Japan

Tel: +81-774-38-4967, Fax: +81-774-38-4996 


\begin{abstract}
High anionic conductivity of $\sim 3.5 \times 10^{-3} \mathrm{Scm}^{-1}$ at room temperature is achieved for $\mathrm{Pb}_{x} \mathrm{Sn}_{2-\mathrm{x}} \mathrm{F}_{4}(x=1.21)$ obtained by annealing a mechanically-milled $\mathrm{PbF}_{2} / \mathrm{SnF}_{2}$ mixture at $400{ }^{\circ} \mathrm{C}$. The observed synchrotron X-ray diffraction patterns indicate formation of a new tetragonal phase at $x=1.1 \sim 1.3$. The Rietveld analysis of the neutron diffraction patterns leads to a unique structure consisting of two alternating layers; a double $\mathrm{Pb}$ layer and a triple layer, each flanked by a single Sn layer. As the Rietveld analysis does not fully converge, the authors further apply high-resolution solid-state NMR $\left({ }^{19} \mathrm{~F},{ }^{119} \mathrm{Sn}\right.$, and $\left.{ }^{207} \mathrm{~Pb}\right)$ to confirm the structure. Further the ${ }^{19} \mathrm{~F}-{ }^{207} \mathrm{~Pb}$ cross-polarization experiment shows that most of $\mathrm{F}^{-}$ions, except for those lie between the double $\mathrm{Pb}$ layers, contribute to its high ionic conductivity. The high conductivity is also attributed to structural flexibility of the triple $\mathrm{Pb}$ layers, indicated by temperature dependent ${ }^{207} \mathrm{~Pb}$ NMR spectra.
\end{abstract}

Keywords: solid-state NMR, solid electrolyte conductive for $\mathrm{F}^{-}$, synchrotron $\mathrm{XRD}$, neutron diffraction 


\section{Introduction}

Solid electrolytes conductive for $\mathrm{F}^{-}$are attracting strong attention as one of promising electrolytes for new batteries using fluoride compounds as positive and negative active materials, which are expected to give high energy density. ${ }^{1-12}$ Among different kinds of solid electrolyte conductive for $\mathrm{F}^{-}, \mathrm{PbSnF}_{4}$ has long been known to show very high conductivity. ${ }^{13}$ Causes of high ionic conductivity of the material are not completely understood yet and structural studies have been done to elucidate the relationship between its structure and the conduction properties. ${ }^{14,15}$ Different methods have been applied to prepare $\mathrm{PbSnF}_{4}$, e.g. mechanical milling, precipitation reaction, and solid-state reaction of a mixture of $\mathrm{PbF}_{2}$ or $\mathrm{Pb}\left(\mathrm{NO}_{3}\right)_{2}$ and $\mathrm{SnF}_{2}$ followed by annealing in inert gas. ${ }^{16,17}$ It has been shown that conductivity depends on its crystal morphology. Unfortunately, the definition of the name of these forms is not common among references, then the authors adopted the one defined in refs. [18] in this work, where the main three forms, monoclinic, tetragonal, and cubic forms, are referred as to the $\alpha$-form, the $\beta$-form, and the $\gamma$-form, respectively. Its polymorphism scheme is roughly written as follows; the $\alpha$-form obtained at lower annealing temperature below ca. $80{ }^{\circ} \mathrm{C}$ is converted to the $\beta$-form at above $80{ }^{\circ} \mathrm{C}$ and further to the other tetragonal form $\left(\beta^{\prime}\right)$ at $\sim 350{ }^{\circ} \mathrm{C}$ and finally to the $\gamma$-form at $\sim 380{ }^{\circ} \mathrm{C}$. Recently, it was shown that the $\gamma$-form can also be obtained by mechanical milling without thermal annealing. ${ }^{19,20}$ Except for the cubic $\gamma$-form, in which $\mathrm{Pb}$ and $\mathrm{Sn}$ occupy the cubic lattice positions, the alignment of the two cations, $\mathrm{Pb}$ and $\mathrm{Sn}$, are common for $\alpha$ and $\beta$, that is, double $\mathrm{Pb}$ layers are flanked by a single $\mathrm{Sn}$ layer, which may be schematically written as [-Sn-Pb-Pb-Sn-], along the $c$ axis. 
So far, various studies have been done to improve its conductivity. For example, Uno et al. examined $\beta-\mathrm{PbSnF}_{4}$ obtained by mechanical milling of $\mathrm{PbF}_{2}$ and $\mathrm{SnF}_{2}$ powders with a certain ratio of the materials. ${ }^{21}$ The conductivity depends on the materials ratio and is largest $\left(\sim 1.6 \times 10^{-3} \mathrm{Scm}^{-1}\right.$ at room temperature $)$ at $\mathrm{PbF}_{2}: \mathrm{SnF}_{2}=50: 50$. Interestingly, the conductivity can be improved by ca. 1 order of magnitude by annealing the pellet in the platinum tube under nitrogen gas at $400{ }^{\circ} \mathrm{C}$ for $6 \mathrm{hrs}$. They attributed the increase to the reduction of grain-boundary impedance due to melting of grains.

This work exploits a Pb-rich region aiming at the higher conductivity; a new crystalline form may appear by annealing at a higher temperature allowed by higher melting point of $\mathrm{Pb}$-rich compounds. Indeed, in this work, it is shown that the annealing temperature of $400{ }^{\circ} \mathrm{C}$ leads the high conductivity of $\mathrm{Pb}_{x} \mathrm{Sn}_{2-x} \mathrm{~F}_{4} \sim 3.5 \times 10^{-3} \mathrm{Scm}^{-1}$ at $x \sim$ 1.21, which is ca. 1.6 times higher than that of the $\beta$-form.

To elucidate the structural origin of the high conductivity, various kinds of technology have been employed in this work; (1) synchrotron X-ray powder diffraction (SXRD), (2) neutron diffraction (ND), and (3) high-resolution solid-state NMR for ${ }^{207} \mathrm{~Pb},{ }^{119} \mathrm{Sn}$, and ${ }^{19} \mathrm{~F}$. Combined analysis using these technologies leads to detailed understanding of the structure of the new tetragonal $\mathrm{Pb}_{x} \mathrm{Sn}_{2-x} \mathrm{~F}_{4}$ form at $x=1.1 \sim 1.3$. The material is referred as the $\beta^{+}$-form from now on. The $\beta^{+}$-form is composed of an alternating two-layers structures; one is the double $\mathrm{Pb}$ layer [-Sn-Pb-Pb-Sn-], whose structure is similar to that in the $\beta$-form. The other is a triple $\mathrm{Pb}$ layer, which is written as [-Sn-Pb-Pb-Pb-Sn-]. Experimental results using NMR show that the $\mathrm{F}^{-}$ions between the two $\mathrm{Pb}$ layers in the double $\mathrm{Pb}$ layer are less mobile but that $\mathrm{F}^{-}$ions among the $\mathrm{Pb}$ layers in the triple $\mathrm{Pb}$ layer are more mobile. The 
latter $\mathrm{F}^{-}$ions causes the higher conductivity of the $\beta^{+}$-form. Further, the temperature-dependent NMR chemical shift of ${ }^{207} \mathrm{~Pb}$ suggests high flexibility of the triple $\mathrm{Pb}$ layer.

\section{Experimental Section}

\subsection{Sample Preparation}

Several $\mathrm{Pb}_{x} \mathrm{Sn}_{2-x} \mathrm{~F}_{4}$ samples $(x=1.52 \sim 0.96)$ were prepared from mixture of $\mathrm{PbF}_{2}$ (Kojundo Chemical Laboratory Co., Ltd., 99.9\%) and $\mathrm{SnF}_{2}$ (Kojundo Chemical Laboratory Co., Ltd., 99.9\%) powders as the starting materials. A mixture of these materials in different ratio was mechanically milled at room temperature by a planetary ball mill using a zirconia pot with 10 zirconia balls. The rotation speed was $600 \mathrm{rpm}$ and the milling time was $6 \mathrm{~h}$. The prepared amorphous powders were annealed at $400{ }^{\circ} \mathrm{C}$ for $1 \mathrm{~h}$ in an alumina crucible. The high annealing temperature $400{ }^{\circ} \mathrm{C}$, which is close to the melting point (ca. $390{ }^{\circ} \mathrm{C}$ ) of $\mathrm{Pb}_{x} \mathrm{Sn}_{2-x} \mathrm{~F}_{4}$ with $x \sim 1$, was selected not for melting the grain boundary in order to enhance ionic conductivity of the pellet but for leading to the formation of a new phase of high conductivity for $\mathrm{F}^{-}$in mechanically milled powder. In fact, all samples obtained after annealing at $400{ }^{\circ} \mathrm{C}$ were smooth powder, and reduction of grain-boundary impedance due to melting is thus less likely for all samples examined. The sample prepared from a 1:1 mixture was annealed at $200{ }^{\circ} \mathrm{C}$ to prepare the $\mathrm{PbSnF}_{4}$ sample in the $\beta$-form; $\beta$ - $\mathrm{PbSnF}_{4}$ sample, hereafter. All the processes were performed in a dry Ar atmosphere.

The mole ratios of $\mathrm{Pb}$ and $\mathrm{Sn}(\mathrm{Pb}: \mathrm{Sn}=x: 2-x)$ in the annealed samples were determined by using inductively coupled plasma spectrometer (ICP, ICP-8000E, Shimadzu). The mole 
ratios in the $\beta-\mathrm{PbSnF}_{4}$ sample were found to be $0.96: 1.04$, and the ratios for the samples annealed at $400{ }^{\circ} \mathrm{C}$ are designated by the $x$ value.

Electrical conductivities were measured for the cold-pressed pelletized samples with $10 \mathrm{~mm}$ in diameter and about $1 \mathrm{~mm}$ in thickness $(200 \mathrm{mg})$. Gold electrodes were formed on both sides of samples. AC impedance measurements were carried out in a dry $\mathrm{Ar}$ atmosphere using an impedance analyzer (SI1260, Solartron) in the frequency range of 0.1 $\mathrm{Hz}$ to $1 \mathrm{MHz}$. The temperature range of the measurements was from -35 to $140^{\circ} \mathrm{C}$.

\subsection{Synchrotron X-ray powder diffraction (SXRD)}

Synchrotron X-ray powder diffraction (SXRD) measurements were performed at an undulator beamline, BL28XU in SPring-8, Japan in the transmission geometry. The powder samples were sealed in a borosilicate glass capillary (wall thickness $=0.01 \mathrm{~mm}$ and outer diameter $=0.3 \mathrm{~mm}$ ) and rotated by a spinner during the measurement. The incident X-ray monochromated by a Si (220) channel-cut monochromator with a wavelength of $\lambda=$ $0.050043 \mathrm{~nm}$ (calculated by using $\mathrm{CeO}_{2}$ as a standard) was used with a beam size of 0.5 $\mathrm{mm}$ by $0.5 \mathrm{~mm}$ shaped by a quadrant slit. The intensity of the incident X-ray was monitored by an ionization chamber with $\mathrm{N}_{2}$ and Ar gas flow located upstream of the sample, used for the normalization of the XRD data. The X-ray transmitted from the sample was blocked by a lead direct stopper located downstream of the sample to suppress the air scattering. The diffraction patterns were measured using a two-dimensional pixel array detector, Pilatus $100 \mathrm{~K}$ (Dectris), mounted on the $2 \theta$ arm of the goniometer with the camera length of $\sim 1000$ $\mathrm{mm}$. The angle conversions from the diffraction images to XRD profiles were carried out 
by integration along a circular arc with the histogram method ${ }^{22}$ in combination with a $3 \times 3$ super-sampling method.

\subsection{Neutron diffraction (ND)}

Neutron diffraction data were collected on the time-of-flight neutron diffractometer, SPICA at MLF (Materials and Life science experimental Facility) in J-PARC (Japan Proton Accelerator Research Complex). ${ }^{23}$ The sample was installed in a cylindrical $6 \mathrm{~mm}$ diameter vanadium can. The range of wavelength of the neutron beam, which can be used for analysis, was from 0.05 to $0.98 \mathrm{~nm}$. The diffraction pattern was collected using all detectors in the range of $10^{\circ}<2 \theta<175^{\circ}$. The $90^{\circ}$ bank $\left(70^{\circ}<2 \theta<110^{\circ}\right)$ data, which covered the $d$ space range from 0.03 to $0.58 \mathrm{~nm}$, were used for the analysis in this work. The structural parameters were refined with the program, Z-Rietveld. ${ }^{23}$

\subsection{NMR measurement}

The NMR measurements were made using a JEOL ECA600 NMR spectrometer with a triple-tuned MAS probe (Agilent Technologies Inc.) for a $1.6 \mathrm{~mm}$ rotor at $14 \mathrm{~T}$. The resonance frequencies for ${ }^{19} \mathrm{~F},{ }^{119} \mathrm{Sn}$, and ${ }^{207} \mathrm{~Pb}$ were $564 \mathrm{MHz}, 224 \mathrm{MHz}$, and $126 \mathrm{MHz}$, respectively. The ${ }^{19} \mathrm{~F}$ chemical shifts were calibrated in ppm relative to $\mathrm{CCl}_{3} \mathrm{~F}$ adopting the ${ }^{19} \mathrm{~F}$ chemical shift for $\mathrm{LiF}\left(-203 \mathrm{ppm}^{24}\right)$ as an external reference. The ${ }^{119} \mathrm{Sn}$ chemical shifts were calibrated in ppm relative to $\mathrm{Sn}\left(\mathrm{CH}_{3}\right)_{4}$ by adopting the ${ }^{119} \mathrm{Sn}$ chemical shift for $\mathrm{SnO}_{2}$ $\left(-603 \mathrm{ppm}^{25}\right)$ as an external reference. ${ }^{207} \mathrm{~Pb}$ chemical shifts were calibrated in ppm relative 
to saturated aqueous solution of $\mathrm{Pb}\left(\mathrm{NO}_{3}\right)_{2}$. The temperature-calibration experiment was done using ${ }^{207} \mathrm{~Pb} \mathrm{NMR}$ of $\mathrm{Pb}\left(\mathrm{NO}_{3}\right)_{2} .{ }^{26}$

The MAS NMR spectra were observed by using a single-pulse method or a cross-polarization (CP) method. Except for ${ }^{19} \mathrm{~F}$ experiments, the Hahn echo was used with the echo-delay time being $1 / v_{\mathrm{R}}-p w / 2$, where $v_{\mathrm{R}}$ is the MAS spinning frequency and $p w$ is the $\pi$ pulse length. The $\mathrm{CP}$ experiment between ${ }^{19} \mathrm{~F}$ and ${ }^{207} \mathrm{~Pb}$ spins was made by the conventional constant-amplitude $\mathrm{CP}$ pulse sequence. The rf amplitudes used in $\mathrm{CP}$ was ca. $40 \mathrm{kHz}$ for ${ }^{19} \mathrm{~F}$ and ca. $33 \mathrm{kHz}$ for ${ }^{207} \mathrm{~Pb}$, and the contact time of $0.8 \mathrm{~ms}$ was used. The ${ }^{207} \mathrm{~Pb}$ spin-lattice relaxation times in the rotating frame $\left(T_{1 \rho}\right)$ under the same rf amplitude were measured under MAS by using the conventional spin-lock method with the recovery data being fitted to a single exponential curve. To examine the distance information among the $\mathrm{Pb}$ sites, we applied the two-dimensional (2D) Radio Frequency Driven Recoupling (2D-RFDR) ${ }^{27}$ It was performed with an experimentally optimized $\pi$ pulse length of $6.8 \mu \mathrm{s}$ using XY16 phase cycling and the mixing time of $9.6 \mathrm{~ms}$. The 2D RFDR spectrum was observed using $50 t_{1}$ increments and $128 t_{2}$ complex points. The experimental data sets were zero-filled in both the $t_{1}$ and $t_{2}$ dimensions to form a $1024 \times 1024$ data matrix before 2D Fourier Transformation with $200 \mathrm{~Hz}$ exponential broadening. The MAS frequency was $20 \mathrm{kHz}$ for RFDR and $25 \mathrm{kHz}$ for other experiments 


\section{Results and Discussion}

For the $\mathrm{Pb}_{x} \mathrm{Sn}_{2-x} \mathrm{~F}_{4}(x=0.96 \sim 1.52)$ samples annealed at $400{ }^{\circ} \mathrm{C}$, its observed conductivity at room temperature (Figure 1) depends on the mole ratios $(x)$ of $\mathrm{Pb}$ and $\mathrm{Sn}$. Note that the conductivity for the $\beta-\mathrm{PbSnF}_{4}$ sample $\left(\sim 2.2 \times 10^{-3} \mathrm{Scm}^{-1}\right)$ is comparable to that reported previously for $\beta-\mathrm{PbSnF}_{4}$ prepared without annealing $\left(\sim 1.6 \times 10^{-3} \mathrm{Scm}^{-1}\right)^{21}$ and $\beta-\mathrm{PbSnF}_{4}$ prepared with annealing at $200{ }^{\circ} \mathrm{C}\left(\sim 1.6 \times 10^{-3} \mathrm{Scm}^{-1}\right) .{ }^{19}$ The conductivity values of the samples with $x=1.15 \sim 1.25$ are higher than that of the $\beta-\mathrm{PbSnF}_{4}$ sample. The sample prepared by cold pressing of the $\mathrm{Pb}_{x} \mathrm{Sn}_{2-x} \mathrm{~F}_{4}$ powder showed the ionic conductivity as high as $\sim 3.5 \times 10^{-3} \mathrm{Scm}^{-1}$ at $x=1.21$. The value was ca. 1.6 times higher than that of the $\beta$-form at $\mathrm{x}=0.96$.

Figure 2 shows the SXRD patterns of the $\mathrm{Pb}_{x} \mathrm{Sn}_{2-x} \mathrm{~F}_{4}(x=0.96 \sim 1.52)$ samples annealed at $400{ }^{\circ} \mathrm{C}$ and that of the $\beta-\mathrm{PbSnF}_{4}$ sample $(x=0.96)$. The observed $\beta-\mathrm{PbSnF}_{4}$ pattern is consistent with those reported previously. ${ }^{16,28}$ The characteristic SXRD pattern at $2 \theta=$ $13 \sim 17^{\circ}$ of the $x=1.52$ sample annealed at $400{ }^{\circ} \mathrm{C}$ indicates that this sample takes the $\gamma$-form, ${ }^{28}$ and the $x=0.96$ sample is the $\alpha$-form..${ }^{16}$ It is worthy to note that, similar to the $\alpha$-form obtained at lower annealing temperature below ca. $80^{\circ} \mathrm{C}$, the present $\alpha$-form showed phase transition to the $\beta$-form at above $80{ }^{\circ} \mathrm{C}$. This phase transition behavior also shows that the two $\alpha$-forms are same. However, it should be mentioned that reproducibility of the formation of the pure $\alpha$-form is not good as compared to those of the other forms. In fact, many samples starting from the $\mathrm{Pb}: \mathrm{Sn}=1: 1$ mixture bear the $\mathrm{SXRD}$ patterns consisted of the $\alpha$ - and $\beta / \beta^{+}$-forms.

The SXRD patterns of the $x=1.15 \sim 1.25$ samples, whose conductivities are higher than that of the $\beta-\mathrm{PbSnF}_{4}$ sample (Figure 1), resemble the SXRD pattern of the $\beta-\mathrm{PbSnF}_{4}$ 
sample. Detailed analysis of the patterns, however, shows that there is an apparent shift of the peak at around $2 \sim 3^{\circ}$ designated by a round-square box in Figure 2; the peak appeared at ca. $2.5^{\circ}$ for the $\alpha$ - and $\beta$-forms moves toward the lower angle (ca. $2.2^{\circ}$ ) for the $x=$ 1.15 1.25 samples. This indicates elongation of the $c$ axis in these samples, in other words, the structure of these samples (the $\beta^{+}$-form) is new.

In summering the observed relationship between the crystalline form and its conductivity at room temperature, the highest conductivity $\sim 3.5 \times 10^{-3} \mathrm{Scm}^{-1}$ should be ascribed to for $\beta^{+}$at $x=1.21$, while the $\beta$-form bears slightly lower conductivity of $\sim 2.2$ $\times 10^{-3} \mathrm{Scm}^{-1}$. The conductivity for the other two forms $(\alpha$ and $\gamma)$ is much lower; $\sim 0.93$ $\times 10^{-3} \mathrm{Scm}^{-1}$ for the $\alpha$-form and $\sim 0.83 \times 10^{-3} \mathrm{Scm}^{-1}$ for the $\gamma$-form. It is of interest to examine the structural feature of the $\beta^{+}$-form in order to understand its high conductivity.

The neutron diffraction (ND) experiment was applied to examine its structure. The structural parameters were refined with space group P4/nmm (129) by the Rietveld method using the program, Z-Rietveld. Among the three $\beta^{+}$samples $(x=1.15,1.21,1.25)$, the best fitting was obtained for the $x=1.15$ sample. However, the fitting was still not good enough to lead a fully converged structure. The Rietveld refinement pattern of the $\beta^{+}-\mathrm{PbSnF}_{4}$ sample $(x=1.15)$ at room temperature is shown in Supporting Information as Figure S1, and the packing of $\beta^{+}-\mathrm{PbSnF}_{4}$ in the unit cell is shown in Figure 3. It should be pointed out here that the Rietveld analysis of the SXRD data also gave a structure (not converged) almost identical to that shown in Figure 3. As the $R$ factors for fitting of the ND data are rather small $\left(R_{\mathrm{wp}}=0.08388, R_{\mathrm{e}}=0.04018, R_{\mathrm{F}}=0.21109\right)$, we proceeded with the deduced structure for further examination. 
It is suggested that the $\beta^{+}$-form consists of two alternating layers; one layer resembles to the double layer of the $\beta$-form (the region designated by a two-way arrow in Figure 3), while the other layer has a triple $\mathrm{Pb}$ layer flanked by a single $\mathrm{Sn}$ layer. The calculated chemical formula is $\mathrm{Pb}_{5} \mathrm{Sn}_{4} \mathrm{~F}_{18}(Z=1)$. For direct comparison with the $\beta$-form, we may write this as $\mathrm{Pb}_{1.11} \mathrm{Sn}_{0.89} \mathrm{~F}_{4}(Z=4.5)$. In the following, we refer simply to it as $\beta^{+}-\mathrm{PbSnF}_{4}$. Note that the calculated $x$ value for the $\beta^{+}$-form is $x=1.11$, which is close to the $x$ value of the sample $(x=1.15)$ used for the ND analysis. Interestingly, better conductivity is achieved for a slightly larger value of $x=1.21$, indicating enhancement of conductivity by structural disorder brought about by additional $\mathrm{Pb}$. One possible assignment of the excess $\mathrm{Pb}$ may be an extra triple $\mathrm{Pb}$ layer; the layer structure can be written as -[3]-[2]-[3]-[3]*-[2]-[3]-, where [n] exhibits the $n$-Pb layer with the flanking Sn layers, and [3]* indicates the extra triple $\mathrm{Pb}$ layer. Such disorder in a long-range structure would disturb the Rietveld analysis of the ND experiment. Further, the Rietveld fitting becomes difficult because of large anisotropic thermal parameters of $\mathrm{F}$ atoms reflecting its facile motion and also of partial site occupancies, which enable efficient defect diffusion ${ }^{29}$ (ion conductivity). In this work, to confirm the local structure of $\beta^{+}-\mathrm{PbSnF}_{4}$ suggested by the analysis of the SXRD and ND results, we apply high-resolution solid-state NMR, which is a powerful mean to examine the local structure without being disturbed by the long-range disorder. All constitute elements of $\mathrm{PbSnF}_{4}$ are NMR active $\left({ }^{19} \mathrm{~F},{ }^{119} \mathrm{Sn}\right.$, and $\left.{ }^{207} \mathrm{~Pb}\right)$, and among them, ${ }^{207} \mathrm{~Pb}$-NMR would be of interesting as three different $\mathrm{Pb}$ sites, namely, two sites in the triple $\mathrm{Pb}$ layer and one in the double $\mathrm{Pb}$ layer are suggested. In the following NMR measurement, we examine the $x=1.21$ sample as the $\beta^{+}-\mathrm{PbSnF}_{4}$ sample and compare 
with the results of $\beta-\mathrm{PbSnF}_{4}{ }^{29}$

Figure 4 compares ${ }^{19} \mathrm{~F},{ }^{119} \mathrm{Sn}$, and ${ }^{207} \mathrm{~Pb}$ MAS NMR spectra of the two samples ( $\beta$ and $\beta^{+}$). All spectra were taken by using the single-pulse sequence without the Hahn echo for ${ }^{19} \mathrm{~F}$, and with the Hahn echo for ${ }^{119} \mathrm{Sn}$ and ${ }^{207} \mathrm{~Pb}$. The ${ }^{207} \mathrm{~Pb}$ spectrum of the $\beta^{+}$sample taken by using ${ }^{19} \mathrm{~F}$ to ${ }^{207} \mathrm{~Pb} \mathrm{CP}$ is also given, which will be discussed afterward.

As there are several crystallographically different $F$ sites in the $\beta$ - and $\beta^{+}$-forms, one may naively expect to find several signals in the ${ }^{19} \mathrm{~F}$ MAS spectra. However, the two samples exhibit only one relatively sharp ${ }^{19} \mathrm{~F}$ signal, which is ascribable to motional averaging of the chemical-shift differences among the different $F$ sites. The narrower linewidth of the ${ }^{19} \mathrm{~F}$ signal of the $\beta^{+}$sample may indicate faster ${ }^{19} \mathrm{~F}$ motion in the $\beta^{+}$sample. The origin of the apparent chemical-shift difference between the two ${ }^{19} \mathrm{~F}$ spectra should be attributable to differences of the local structures in the two forms.

Similar difference of the isotropic shifts is also observed for the ${ }^{119} \mathrm{Sn}$ spectra in Figure 4, in which the spinning sidebands marked by asterisks appear. It is notable that the MAS spinning side-band patterns are quite similar for these two samples, which indicates similar local environment for the Sn nuclei in the two forms. The characteristic MAS pattern was attributed to the local coordination structure of $\mathrm{Sn}$ in the $\beta$-form; four $4 f \mathrm{~F}$ atoms and one $2 c$ $\mathrm{F}$ atom are placed one-sidedly thus leading the large chemical-shielding anisotropy. Detailed analysis of the ${ }^{119} \mathrm{Sn}$ lineshape of the $\beta$-form including effects of $\mathrm{F}^{-}$motion is found in Ref. [29]. To conclude, the almost same sideband patterns for the $\beta$ and $\beta^{+}$-forms suggest an almost identical local coordination structure of Sn for them, which is consisted with the structure obtained by the ND experiments. 
In contrast to the ${ }^{19} \mathrm{~F}$ and ${ }^{119} \mathrm{Sn}$ results, there is salient difference in the ${ }^{207} \mathrm{~Pb}$ spectra; there are three ${ }^{207} \mathrm{~Pb}$ signals in the spectrum of the $\beta^{+}$sample, while only one signal is obtained for the $\beta$ sample. For ease of discussion, the three signals are numbered as "a" to "c" from the higher-frequency side (Figure 4) and the corresponding ${ }^{207} \mathrm{~Pb}$ nuclei as $\mathrm{Pb}$-a to $\mathrm{Pb}$-c. The area-intensity ratio for the three signals obtained by lineshape decomposition (Figure 5) is $40.2: 19.7: 40.1 \sim 2: 1: 2$. It appears that the ${ }^{207} \mathrm{~Pb}$ signal-c at ca. $-75 \mathrm{ppm}$ corresponds to the ${ }^{207} \mathrm{~Pb}$ signal in the $\beta$-form, and we assign $\mathrm{Pb}-\mathrm{c}$ to $\mathrm{Pb}(\mathrm{Pb} 5)$ in the double $\mathrm{Pb}$ layer in the $\beta^{+}$-form (Figure 3 ).

The remaining two $\mathrm{Pb}$ signals are assigned to the two $\mathrm{Pb}$ nuclei in the triple $\mathrm{Pb}$ layer, and, with the ratio obtained from the $\mathrm{Pb}$-signal intensities of $\mathrm{Pb}-\mathrm{a}: \mathrm{Pb}-\mathrm{b}=2: 1$, we assign $\mathrm{Pb}-\mathrm{a}$ to $\mathrm{Pb} 2$ and $\mathrm{Pb} 4$ sitting at the outside of the triple $\mathrm{Pb}$ layer and $\mathrm{Pb}-\mathrm{b}$ to $\mathrm{Pb} 3$ at the inside of the layer. To confirm $\mathrm{Pb}-\mathrm{a}$ and $\mathrm{Pb}-\mathrm{b}$ are in the same triple layer, we applied ${ }^{207} \mathrm{~Pb}-{ }^{207} \mathrm{~Pb}$ dipolar-correlation experiment by using the RFDR method.

Figure 6 shows the ${ }^{207} \mathrm{~Pb}_{-}{ }^{207} \mathrm{~Pb}$ 2D-RFDR spectrum of the $\beta^{+}-\mathrm{PbSnF}_{4}$ sample taken with the mixing time of $9.6 \mathrm{~ms}$ and the MAS spinning speed of $20 \mathrm{kHz}$. Even though the natural abundance of ${ }^{207} \mathrm{~Pb}$ is low (ca. $21 \%$ ), we found cross peaks between $\mathrm{Pb}$-a and $\mathrm{Pb}$-b. The observation of the cross peaks indicates that $\mathrm{Pb}-\mathrm{a}$ and $\mathrm{Pb}-\mathrm{b}$ are in close proximity, which confirms the above assignment, namely, $\mathrm{Pb}-\mathrm{a}$ and $\mathrm{Pb}-\mathrm{b}$ belong to the triple $\mathrm{Pb}$ layer. To conclude, $\mathrm{Pb}$-a is assigned to the outer $\mathrm{Pb}$ in the triple $\mathrm{Pb}$ layer $(\mathrm{Pb} 2$ and $\mathrm{Pb} 4)$ and $\mathrm{Pb}-\mathrm{b}$ to the inner one $(\mathrm{Pb}-3)$. The $\mathrm{Pb}-\mathrm{a}: \mathrm{Pb}-\mathrm{b}: \mathrm{Pb}-\mathrm{c}=2: 1: 2$ ratio obtained from the ${ }^{207} \mathrm{~Pb}$ spectrum (Figure 5) further requires the ratio of the triple and the double layers is close to $1: 1$, which is indeed consistent with the alternating structure in Figure 3. It is worthy to point out here 
that the three ${ }^{207} \mathrm{~Pb}$ signals were also observed for the other two $\beta^{+}$samples $(x=1.15$ and $1.25)$.

The Pb-c signal disappears in the 2D-RFDR spectrum. This is explained as follows. The broad linewidth of the ${ }^{207} \mathrm{~Pb}$-c signal is ascribable to inhomogeneous one due to distribution of local environment of $\mathrm{Pb}-\mathrm{c}$. The $\mathrm{Pb}-\mathrm{Pb}$ magnetization transfer occurs among the different $\mathrm{Pb}-\mathrm{c}$ sites during the mixing time in the RFDR experiment, which leads to scattering of the $\mathrm{Pb}$ intensity among the broad signal, i.e., the observed reduction of the signal.

Having established the structure of the $\beta^{+}$-form, let us now turn to the relationship between its unique structure and high conductivity. It is apparent that facile transportation of $\mathrm{F}^{-}$ions is supported by its unique $\mathrm{Sn}-\mathrm{Pb}$ layer structure with the "gap" between the $\mathrm{Pb}$ layer and the Sn layer that offers a conduction path. The fast $\mathrm{F}^{-}$motion should reduce the ${ }^{19} \mathrm{~F}-{ }^{207} \mathrm{~Pb}$ dipolar interactions and it was in fact observed that ${ }^{19} \mathrm{~F}$ dipolar decoupling brings no apparent line narrowing for the ${ }^{207} \mathrm{~Pb}$ MAS spectra (not shown). As the strength of the ${ }^{19} \mathrm{~F}-{ }^{207} \mathrm{~Pb}$ dipolar interactions at the three different $\mathrm{Pb}$ sites is a good measure of the mobility of the $\mathrm{F}^{-}$ions in the conduction path, that is, through the double $\mathrm{Pb}$ layer and through the triple $\mathrm{Pb}$ layers, the ${ }^{19} \mathrm{~F}$ to ${ }^{207} \mathrm{~Pb} \mathrm{CP}$ experiments were pursued; the $\mathrm{CP}$ transfer rate is sensitive to the strength of the ${ }^{19} \mathrm{~F}^{207} \mathrm{~Pb}$ dipolar interaction. It is remarkable that only the $\mathrm{Pb}-\mathrm{c}$ signal does appear (the red spectrum in Figure $4 \mathrm{f}$ ). This means that the ${ }^{19} \mathrm{~F}-{ }^{207} \mathrm{~Pb}$ dipolar interaction among ${ }^{19} \mathrm{~F}$ and ${ }^{207} \mathrm{~Pb}$ at $\mathrm{Pb}-\mathrm{a}$ and $\mathrm{Pb}-\mathrm{b}$ in the triple layer is weak and/or the ${ }^{207} \mathrm{~Pb}$ spin-lattice relaxation time in the rotating frame $\left(T_{1 \rho}\right)$ is short. The latter is negated because the observed $T_{1 \rho}$ values for $\mathrm{Pb}-\mathrm{a}$ and $\mathrm{Pb}-\mathrm{c}(\sim 10 \mathrm{~ms})$ are much longer than 
that for $\mathrm{Pb}-\mathrm{c}(\sim 3 \mathrm{~ms})$ and the contact time for the $\mathrm{CP}$ experiment $(0.8 \mathrm{~ms})$. The result of the $\mathrm{CP}$ experiment thus leads us to conclude that the $\mathrm{F}^{-}$ions around $\mathrm{Pb}-\mathrm{a}$ and $\mathrm{Pb}-\mathrm{b}$ are mobile, and the ones around $\mathrm{Pb}-\mathrm{c}$ are less mobile. Additionally, the ${ }^{119} \mathrm{Sn}-{ }^{19} \mathrm{~F} \mathrm{CP}$ experiment for the $\beta^{+}$-form did not give any ${ }^{119} \mathrm{Sn}$ signals (not shown). These data indicate that all $\mathrm{F}$ ions are mobile except for $\mathrm{F} 8(2 \mathrm{~b})$ in the $\beta^{+}$-form, that is, the ratio of the mobile $\mathrm{F}^{-}$ions in $\beta^{+}$-form is much larger than that in the $\beta$-form. This high concentration of mobile $\mathrm{F}^{-}$leads to the higher conductivity of the $\beta^{+}$-form.

To examine further the origins of the higher conductivity of these tetragonal forms, temperature dependence of the ${ }^{207} \mathrm{~Pb}$ MAS spectrum was examined. Temperature dependence of the ${ }^{19} \mathrm{~F}$ and ${ }^{119} \mathrm{Sn}$ spectra is in due course and detailed ion dynamics will be discussed. Figure 7 shows the temperature dependence of the ${ }^{207} \mathrm{~Pb}$ MAS spectra of the $\beta^{+}$-form and the $\beta$-form. Indeed, all signals show lower-frequency shift at higher temperature. Similar to the spectral decomposition in Figure 5, the $\beta^{+}$-form spectra were fitted to a sum of the three signals. The chemical shifts at each temperature for the three ${ }^{207} \mathrm{~Pb}$ signals of the $\beta^{+}$-form thus obtained are plotted with that of the $\beta$-form in Figure S2 of the Supporting Information. It is shown that, in the $\beta^{+}$-form, the $\mathrm{Pb}$-a signal in the triple $\mathrm{Pb}$ layer shifts more than the other $\mathrm{Pb}$ signals. This indicates that the triple $\mathrm{Pb}$ layer is more flexible than the double $\mathrm{Pb}$ layer. The shift of the $\mathrm{Pb}$ signal in the $\beta$-form is comparable to those of $\mathrm{Pb}-\mathrm{b}$ and $\mathrm{Pb}-\mathrm{c}$ in the $\beta^{+}$-form. These results indicate that the flexibility of the $\mathrm{Pb}$ layers in both of the $\beta$-form and the $\beta^{+}$-form alleviates steric hindrance for conduction of $\mathrm{F}^{-}$ ions in the layer and leads to higher conductivity in $\beta^{+}$-form. 


\section{Summary}

A new compound of $\mathrm{Pb}_{\mathrm{x}} \mathrm{Sn}_{2-\mathrm{x}} \mathrm{F}_{4}(\mathrm{x} \sim 1.21)$ with a layered crystalline structure was prepared using the high annealing temperature of $400{ }^{\circ} \mathrm{C}$. The SXRD study suggested that the compound is in the tetragonal structure and has a longer $c$ axis as compared to that of the reported tetragonal form, which has been described as the $\beta$-form. ${ }^{16,28}$ The new form named here as the $\beta^{+}$-form showed the anionic conductivity at room temperature as high as $\sim 3.5 \times 10^{-3} \mathrm{Scm}^{-1}$ for the $x=1.21$ sample, that is appreciably higher than the value obtained for the other form of $\mathrm{PbSnF}_{4} ; \sim 0.93 \times 10^{-3} \mathrm{Scm}^{-1}$ for the monoclinic form, $\sim$ $2.2 \times 10^{-3} \mathrm{Scm}^{-1}$ of the tetragonal $\beta$-form, and $\sim 0.83 \times 10^{-3} \mathrm{Scm}^{-1}$ for the cubic form. Note that the conductivity of $2.5 \times 10^{-3} \mathrm{Scm}^{-1}$ was reported recently for the $\mathrm{Pb}$-rich $(x \sim 1.1)$ cubic form obtained by ball milling without following thermal annealing. ${ }^{20}$

The Rietveld analysis of the neutron diffraction (ND) profile and the synchrotron X-ray diffraction (SXRD) profile did not bring out a fully converged structure. High-resolution solid-state NMR studies of ${ }^{19} \mathrm{~F},{ }^{119} \mathrm{Sn}$, and ${ }^{207} \mathrm{~Pb}$ of the materials gave a lot of information of the structure of the material; (1) the local environment of $\mathrm{Sn}$ in the $\beta^{+}$-form is almost identical to that in the $\beta$-form, (2) there are three $\mathrm{Pb}$ sites in the $\beta^{+}$-form and one of them is attributable to $\mathrm{Pb}$ in a site similar to the $\mathrm{Pb}$ site in the double $\mathrm{Pb}$ layer in the $\beta$-form, and (3) the ratio of the three $\mathrm{Pb}$ sites obtained from the $\mathrm{Pb}$-signal intensities is $2: 1: 2$. These are in fact consistent with the structure derived from the Rietveld analysis of the ND data, that is, an alternating layered structure with the double and the triple $\mathrm{Pb}$ layers.

As for the higher conductivity for $\beta^{+}$, several experimental clues were shown; (1) The 
${ }^{19} \mathrm{~F}^{-207} \mathrm{~Pb} \mathrm{CP}$ magnetization transfer did not occur for the two ${ }^{207} \mathrm{~Pb}$ sites in the triple $\mathrm{Pb}$ layer. (2) The highest conductivity was achieved for $\beta^{+}-\mathrm{Pb}_{\mathrm{x}} \mathrm{Sn}_{2-\mathrm{x}} \mathrm{F}_{4}(x=1.21)$, whose $x$ value is slightly larger than the ideal one for the $\beta^{+}$-form $(x=1.11)$. (2) The chemical shifts of the ${ }^{207} \mathrm{~Pb}$ signals of the $\beta$-form and the $\beta^{+}$-form are temperature dependent. The first point is that the better conductivity of the $\beta^{+}$-form is ascribed to the higher mobility of the $\mathrm{F}^{-}$ions in the triple $\mathrm{Pb}$ layer. The second point is that the structural disorder brought about by the excess $\mathrm{Pb}$, that is considered to increase the amount of the triple layer. This extra triple layer leads to higher conductivity for $\beta^{+}-\mathrm{Pb}_{\mathrm{x}} \mathrm{Sn}_{2-\mathrm{x}} \mathrm{F}_{4}$ at $x=1.21$. The last point is that the structural flexibly of the conduction pathways allows facile ion conduction in these tetragonal $\mathrm{PbSnF}_{4}$ forms in addition to the defect-driven conductivity shown for the $\beta$-form. ${ }^{29}$ The present results may invoke a similar enhancement of conductivity based on flexibility of the conduction pathway postulated for $\mathrm{LiP}_{3} \mathrm{~S}_{11}$ metastable crystal. ${ }^{31}$

ACKNOWLEDGMENTS This work was supported by R\&D Initiative for Scientific Innovation on New Generation Batteries 2 (RISING 2) Project administrated by New Energy and Industrial Technology Development Organization (NEDO). The authors thank Mr. Takashi Moroishi and Mr. Takahiro Terada for their experimental supports. The synchrotron radiation experiments were performed with the approval of JASRI/SPring-8 (Proposals 2015A1013 and 2015B1014). The neutron diffraction experiments were conducted as part of the S-type project of the High Energy Accelerator Research Organization (KEK) (Proposal 2015SP01). The packing structure in Figure 3 was prepared using VESTA. ${ }^{32}$ 
Supporting Information Available: Observed and calculated neutron diffraction profile for $\beta^{+}-\mathrm{PbSnF}_{4}(x=1.14)$ was given in Figure $\mathrm{S} 1$. Temperature dependence of the ${ }^{207} \mathrm{~Pb}$ chemical shifts in $\beta^{+}$- and $\beta-\mathrm{PbSnF}_{4}$ obtained by spectral decomposition was given in Figure S2. This material is available free of charge via the Internet at http://pubs.acs.org. 


\section{References}

1. Reddy, M. A.; Fichtner, M. Batteries based on fluoride shuttle. J. Mater. Chem. 2011, $21,17059-17062$.

2. Fo a review, Gschwind, F.; Rodriguez-Garcia, G.; Sandbeck, D. J. S.; Gross, A.; Weil, M.; Fichtner, M.; Hörmann, N. Fluoride ion batteries: theoretical performance, safety, toxicity, and a combinatorial screening of new electrodes. J. Fluor. Chem. 2016, 182, 76-90.

3. Nowroozi, M. A.; Wissel, K.; Rohrer, J.; Munnangi, A. R.; Clemens, O. LaSrMnO4: Reversible Electrochemical Intercalation of Fluoride Ions in the Context of Fluoride Ion Batteries. Chem. Mater. 2017, 29, 3441-3453.

4. Thieu, D. T.; Fawey, M. H.; Bhatia, H.; Diemant, T. Chakravadhanula, V. S. K.; Behm, R. J.; Kübel, C.; Fichtner, M. $\mathrm{CuF}_{2}$ as Reversible Cathode for Fluoride Ion Batteries. Adv. Funct. Mater. 2017, 27, 1701051 (11 pages).

5. Grenier, A.; Porras-Gutierrez, A. G.; Body, M.; Legein, C.; Chrétien, F.; Raymundo-Piñero, E.; Dollé, M.; Groult, H.; Dambournet, D. Solid Fluoride Electrolytes and Their Composite with Carbon: Issues and Challenges for Rechargeable Solid State Fluoride-Ion Batteries, J. Phys. Chem. C 2017, 121, 24962-24970

6. Okazaki, K.; Uchimoto, Y.; Abe, T.; Ogumi, Z. Charge-discharge behavior of bismuth in a liquid electrolyte for rechargeable batteries based on a fluoride shuttle. ACS Energy Lett. 2017, 2, 1460-1464.

7. Konishi, H.; Minato, T.; Abe, T.; Ogumi, Z. Electrochemical properties of lead fluoride electrode in fluoride shuttle battery. J. Electroanal. Chem. 2018, 826, 60-64. 
8. Konishi, H.; Minato, T.; Abe, T.; Ogumi, Z. Improvement of cycling performance inbismuth fluoride electrodes by controlling electrolyte composition in fluoride shuttle batteries. J. Appl. Electrochem. 2018, 48, 1205-1211.

9. Davis, V. K.; Bates, C. M.; Omichi, K.; Savoie, B. M.; $\quad$ Momcilovic, N.; Xu, Q. M.; Wolf, W. J.; Webb, M. A.; Billings, K. J.; Chou, N. H.; Alayoglu, S.; McKenney, R. K.; Darolles, I. M.; Nair, N. G.; Hightower, A.; Rosenberg, D.; Ahmed, M.; Brooks, C. J.; Miller, T. F.; Grubbs, R. H.; Jones, S. C., Room-temperature cycling of metal fluoride electrodes: Liquid electrolytes for high-energy fluoride ion cells. Science 2018, 362, 1144-1148.

10. Mohammad, I.; Witter, R.; Fichtner, M.; Reddy, M. A. Introducing Interlayer Electrolytes: Toward Room-Temperature High-Potential Solid-State Rechargeable Fluoride Ion Batteries, ACS Appl. Energy Mater. 2019, 2, 1533-1562.

11. Yamanaka, T.; Abe, T.; Nishio, K.; Ogumi, Z. In Situ Observation of Fluoride Shuttle Battery Reactions with Dissolution-Deposition Mechanisms by Raman Microscopy, $J$. Electrochem. Soc. 2019, 166, A635-A640.

12. Yamanaka, T.; Okazaki, K.; Abe, T.; Nishio, K.; Ogumi, Z. Evolution of Reactions of a Fluoride Shuttle Battery at the Surfaces of $\mathrm{BiF}_{3}$ Microclusters Studied by in Situ Raman Microscopy, ChemSusChem 2019, 12, 527 - 534.

13. Réau, J. M.; Lucat, C.; Portier, J.; Hagenmuller, P.; Cot, L.; Vilminot, S. Study of Structural and Electrical-Properties of a New Anion Conductor - $\mathrm{PbSnF}_{4}$. Mater. Res. Bull. 1978, 13, 877-882.

14. For example, Castiglione, M.; Madden, P.A.; Berastegui, P.; and Hull, S. The crystal 
structure of $\alpha-\mathrm{PbSnF}_{4}$ and its anion diffusion mechanism. J Phys Condens Matter, 2005, $17,845-861$.

15. For example, Murray, E.; Brougham, D. F.; Stankovic, J.; Abrahams, I., Conductivity and fluoride ion dynamics in $\alpha-\mathrm{PbSnF}_{4} ;{ }^{19} \mathrm{~F}$ field-cycling NMR and diffraction studies. J Phys Chem C 2008, 112 (14), 5672-5678.

16. Perez, G.; Vilminot, S.; Granier, W.; Cot, L.; Lucat, C.; Reau, J. M.; Portier, J., About the Allotropic Transformations of $\mathrm{PbSnF}_{4}$. Mater Res Bull 1980, 15 (5), 587-593.

17. Collin, A.; Dénès, G.; Roux, D. L.; Madamba, M. C.; Parris, J. M.; Salaün, A., Understanding the phase transitions and texture in superionic $\mathrm{PbSnF}_{4}$ the key to reproducible properties. Int J Inorg Mater 1999, 1, 289-301.

18. Nikol'skaya, O. K.; Demianets, L. N.; Sorokin, N. I., Hydrothermal synthesis and ionic conductivity of $\mathrm{CdF}_{2}$ and low-temperature modifications of $\mathrm{PbF}_{2}$ and $\mathrm{PbSnF}_{4}$. Crystallogr Rep 2002, 47 (4), 695-700.

19. Fujisaki, F.; Mori, K.; Yonemura, M.; Ishikawa, Y.; Kamiyama, T.; Otomo, T.; Matsubara, E.; Fukunaga, T., Mechanical synthesis and structural properties of the fast fluoride-ion conductor $\mathrm{PbSnF}_{4}$. J Solid State Chem 2017, 253, 287-293.

20. Molaiyan, P.; Witter, R., Crystal Phase and Surface Defect Driven Synthesis of $\mathrm{Pb}_{1-\mathrm{x}} \mathrm{Sn}_{\mathrm{x}} \mathrm{F}_{2}$ Solid Solution Electrolyte for Fluoride Ion Batteries. J Electroanal Chem 2019, $845,154-159$.

21. Uno, M.; Onitsuka, M.; Ito, Y.; Yoshikado, S., Synthesis and evaluation of $\mathrm{Pb}_{1-x} \mathrm{Sn}_{x} \mathrm{~F}_{2}$ by mechanical milling. Solid State Ionics 2005, 176 (31-34), 2493-2498.

22. Shimomura, O.; Takemura, K.; Fujihisa, H.; Fujii, Y.; Ohishi, Y.; Kikegawa, T.; 
Amemiya, Y.; Matsushita, T. Application of an imaging plate to high-pressure x-ray study with a diamond anvil cell, Rev. Sci. Instrum. 1992, 63, 967-973.

23. Yonemura, M.; Mori, K.; Kamiyama, T.; Fukunaga, T.; Torii, S.; Nagao, M.; Ishikawa, Y.; Onodera, Y.; Adipranoto, D. S.; Arai, H.; Uchimoto, Y.; Ogumi, Z. Development of SPICA, New Dedicated Neutron Powder Diffractometer for Battery Studies. J. Phys.: Conf. Ser. 2014, 502, 012053.

24. Groß, U.; Rudiger, S.; Grimmer, A. R.; Kemnitz, E. ${ }^{19}$ F-NMR Solid State Investigations of Monovalent Alkali Metal Fluorides and Tetra-alkylammonium Fluorides. J. Fluorine Chem. 2002, 115, 193-199 and references therein.

25. Cossement, C.; Darville, J.; Gilles, J. M.; Nagy, J. B.; Fernandez, C.; Amoureux, J. P., Chemical-Shift Anisotropy and Indirect Coupling in $\mathrm{SnO}_{2}$ and SnO. Magn Reson Chem 1992, 30 (3), 263-270.

26. Bielecki, A.; Brum, D.P. Temperature Dependence of ${ }^{207} \mathrm{~Pb}$ MAS Spectra of Solid Lead Nitrate. An Accurate, Sensitive Thermometer for Variable-temperature MAS. $J$. Magn. Reson. A 1995, 116, 215-220.

27. Bennett, A. E.; Ok, J. H.; Griffin, R. G.; Vega, S. Chemical Shift Correlation Spectroscopy in Rotating Solids Radio Frequency-Driven Dipolar Recoupling and Longitudinal Exchange. J. Chem. Phys. 1992, 96, 8624-8627.

28. Ito, Y.; Mukoyama, T.; Funatomi, H.; Yoshikado, S.; Tanaka, T. The Crystal-Structure of Tetragonal Form PbSnF4, Solid State Ionics 1994, 67, 301-305.

29. Murakami, M.; Morita, Y. Mizuno, M. ${ }^{19} \mathrm{~F} /{ }^{119} \mathrm{Sn} /{ }^{207} \mathrm{~Pb}$ NMR Studies on Ion Dynamics in Tetragonal PbSnF4; Spectroscopic Evidence for Defect-Driven Conductivity. J Phys 
Chem C, 2017, 121, 2627-2634; the ${ }^{19} \mathrm{~F}$ shift in Figure 1 was erroneously referenced to $\delta(\operatorname{LiF})=0$ ppm

30. Ahmad, M.M.; Yamada, K.; and Okuda, T. Fluoride Ion Diffusion of Superionic PbSnF4 Studied by Nuclear Magnetic Resonance and Impedance Spectroscopy, J. Phys. Condens. Matter. 2002, 14, 7233-7244.

31. Murakami, M.; Shimoda, K.; Shiotani, S.; Mitsui, A.; Ohara, K.; Onodera, Y.; Arai, H.; Uchimoto, Y.; and Ogumi, Z. Dynamical Origin of Ionic Conductivity for $\mathrm{Li}_{7} \mathrm{P}_{3} \mathrm{~S}_{11}$ Metastable Crystal as Studied by ${ }^{6 / 7} \mathrm{Li}$ and ${ }^{31} \mathrm{P}$ Solid-State NMR, $J$ Phys Chem $C \mathbf{2 0 1 5}$, $119,24248-24254$.

32. Momma, K.; Izumi, F. VESTA 3 for Three-Dimensional Visualization of Crystal, Volumetric and Morphology Data. J. Appl. Crystallogr. 2011, 44, 1272-1276. 


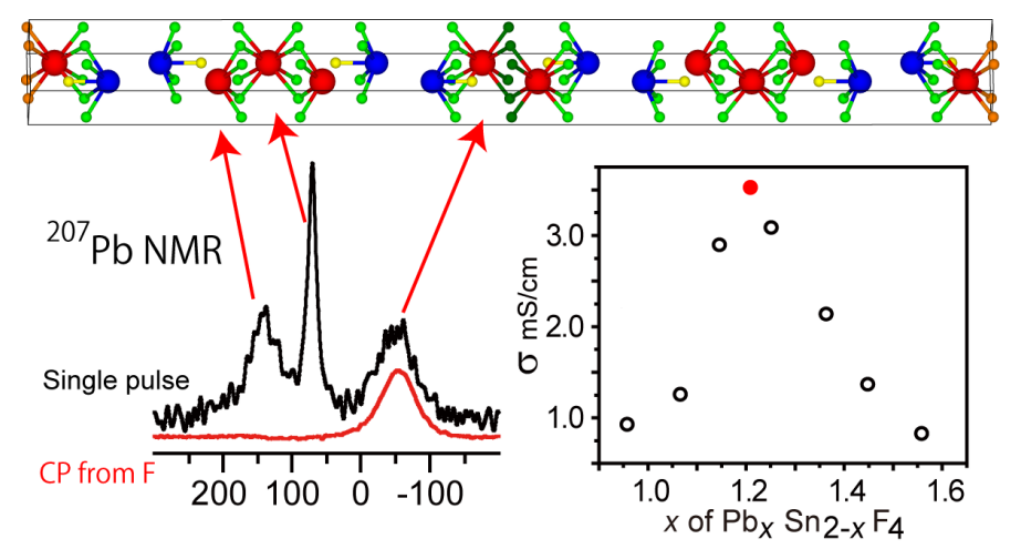

TOC Abstract Graphics 


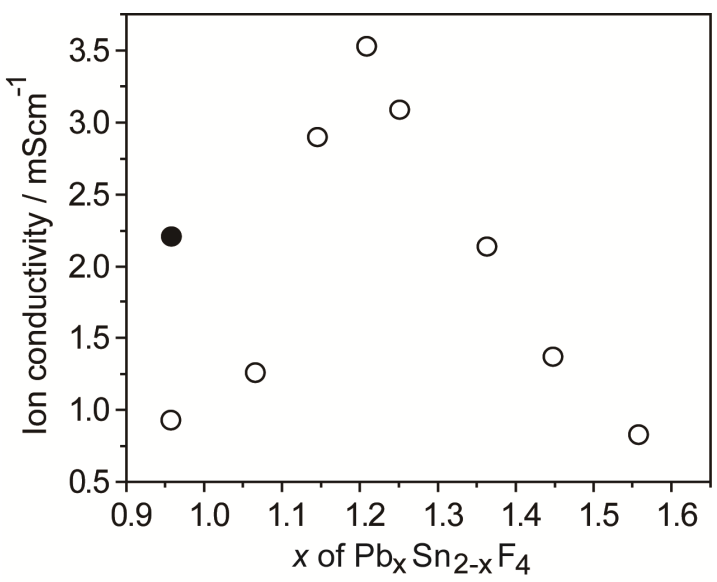

Figure 1. Dependence of conductivity on the $\mathrm{Pb}: \mathrm{Sn}$ molar ratio in the $\mathrm{Pb}_{x} \mathrm{Sn}_{2-x} \mathrm{~F}_{4}$ pressed-powder samples $(x=0.96-1.56)$ anealed at $400{ }^{\circ} \mathrm{C}$ (open circle) and $200{ }^{\circ} \mathrm{C}$ (filled circle). 


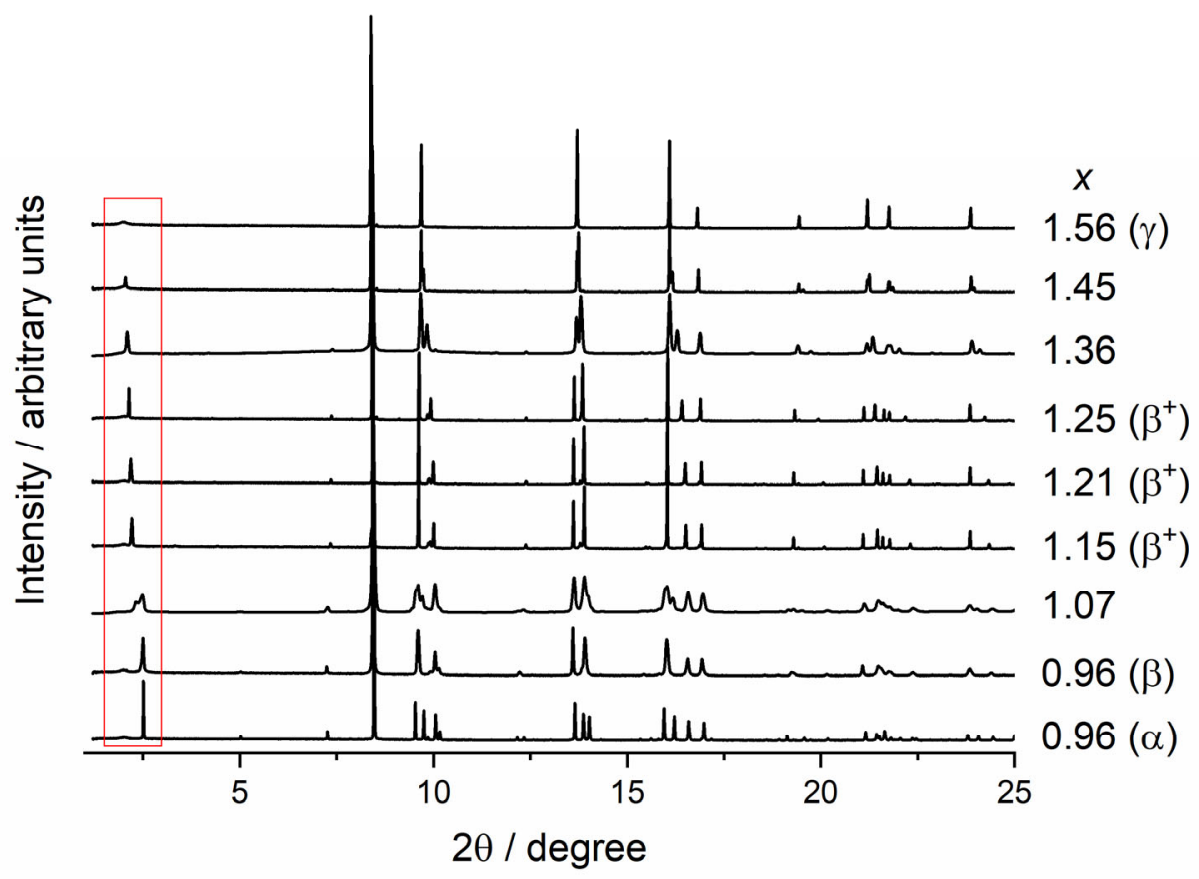

Figure 2. SXRD patterns of the $\mathrm{Pb}_{x} \mathrm{Sn}_{2-x} \mathrm{~F}_{4}(x=0.96-1.56)$ samples. The patterns without labeling are of the transition/mixed states. 


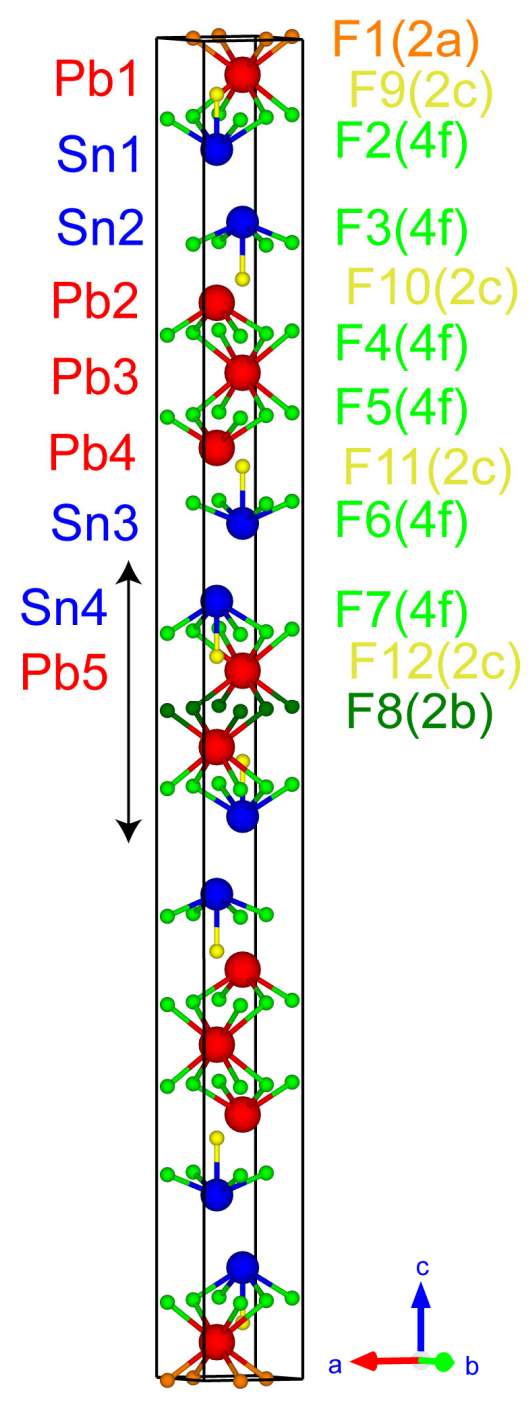

Figure 3. Packing of $\beta^{+}-\mathrm{PbSnF}_{4}$ in the unit cell. $a, b$, and $c$ denotes three crystallographic axes. Blue and red balls are $\mathrm{Sn}$ and, $\mathrm{Pb}$ respectively. The four $\mathrm{F}$ sites ( $2 \mathrm{a}, 2 \mathrm{~b}, 2 \mathrm{c}$, and $4 \mathrm{f})$ are designated by orange, dark-green, yellow, and green, respectively. 


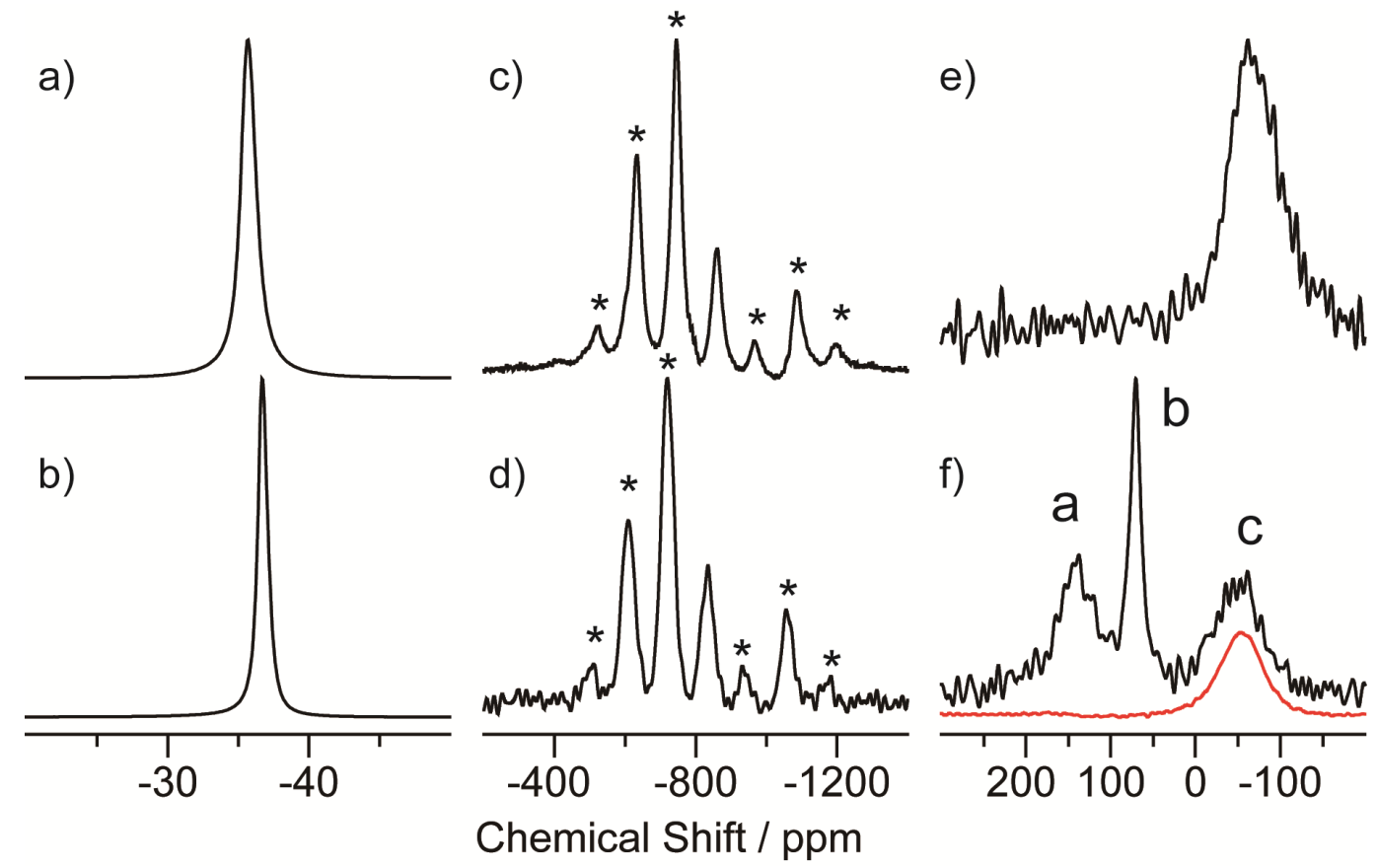

Figure $4 .{ }^{19} \mathrm{~F}(\mathrm{a}, \mathrm{b}),{ }^{119} \mathrm{Sn}(\mathrm{c}, \mathrm{d})$, and ${ }^{207} \mathrm{~Pb}(\mathrm{e}, \mathrm{f}) \mathrm{MAS}$ NMR spectra of the $\beta$ (a, c, and e) and $\beta^{+}\left(\mathrm{b}, \mathrm{d}\right.$, and $\mathrm{f}$ ) samples at ca. $40^{\circ} \mathrm{C}$. An exponential line broadening of $1000 \mathrm{~Hz}$ was applied to ${ }^{119} \mathrm{Sn}$ (c, d) spectra prior to Fourier transformation. Except for the ${ }^{207} \mathrm{~Pb}$ spectrum in red, which was obtained by the ${ }^{19} \mathrm{~F}$ to ${ }^{207} \mathrm{~Pb} \mathrm{CP}$ method, all spectra were taken by using the single-pulse sequence without the Hahn echo for ${ }^{19} \mathrm{~F}$, and with the Hahn echo for ${ }^{119} \mathrm{Sn}$ and ${ }^{207} \mathrm{~Pb}$. The peaks marked by the asterisk are the spinning sidebands. The three signals in the ${ }^{207} \mathrm{~Pb}$ spectrum of the $\beta^{+}$sample (f) are labeled by "a" to "c" as indicated in the figure. 


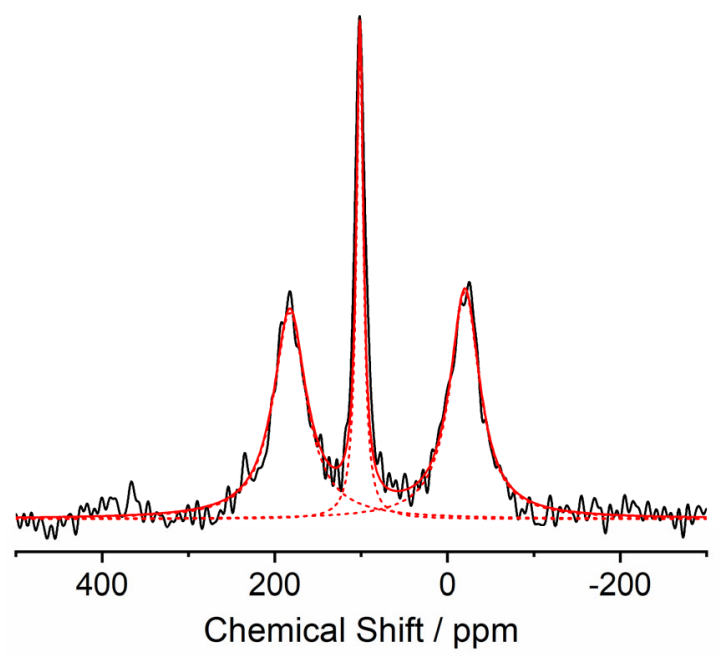

Figure 5. Spectral decomposition of the ${ }^{207} \mathrm{~Pb}$ MAS spectrum of $\beta^{+}-\mathrm{PbSnF}_{4}$ at $80^{\circ} \mathrm{C}$ (the black line) by three Lorentzian lineshapes (the red dotted lines). The sum of the three Lorentzian lineshapes is given by the red solid line. For quantitative analysis, the pulse-repetition time $13 \mathrm{~s}$ was set to be much longer than the spin-lattice relaxation times of the three signals (Pb-a: ca. 1.2 s, Pb-b: ca. 1.6s, and Pb-c: ca. 1.9 s). 


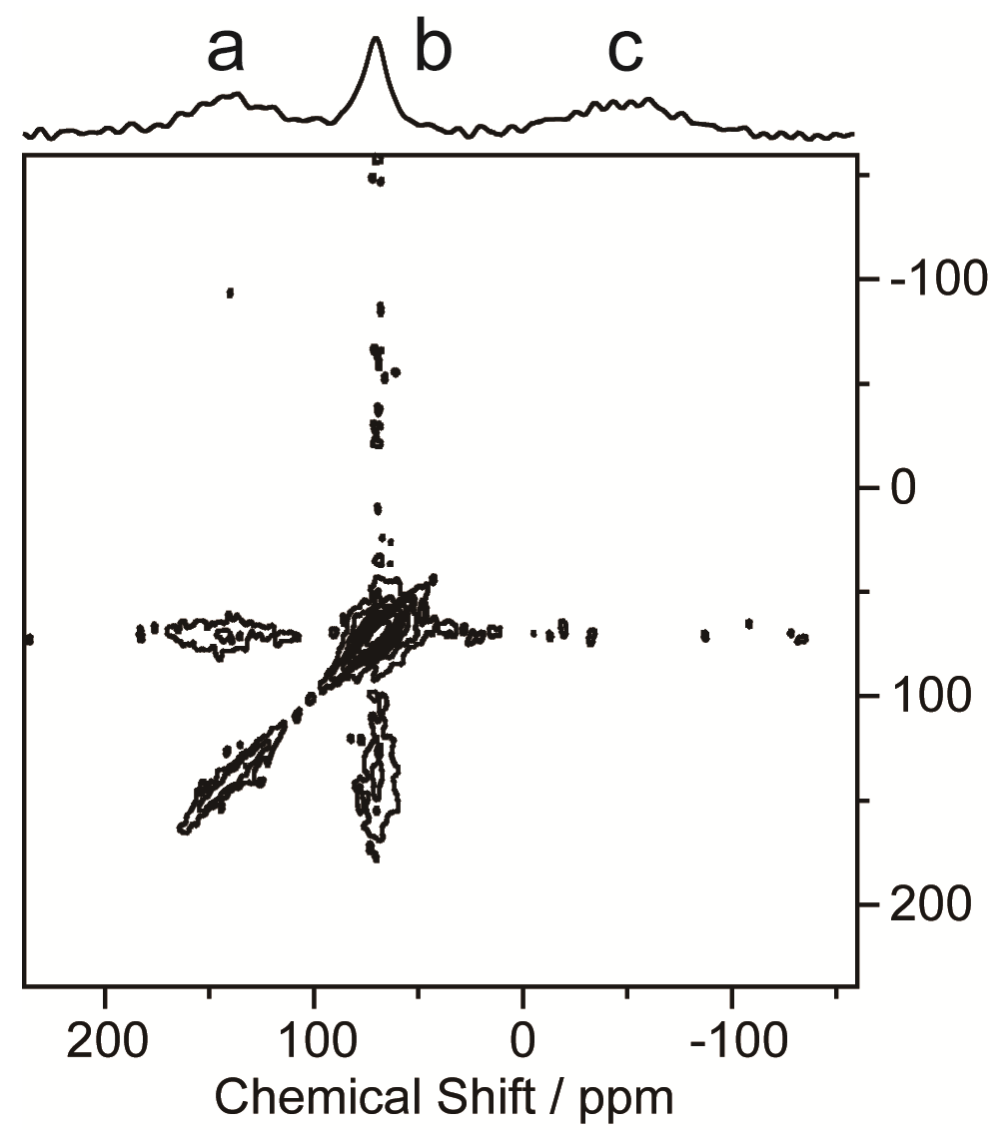

Figure $6 .{ }^{207} \mathrm{~Pb}^{207} \mathrm{~Pb}$ dipolar-correlation RFDR spectrum of $\beta^{+}-\mathrm{PbSnF}_{4}(x=1.21)$ with the mixing time of $9.6 \mathrm{~ms}$ at room temperature. 

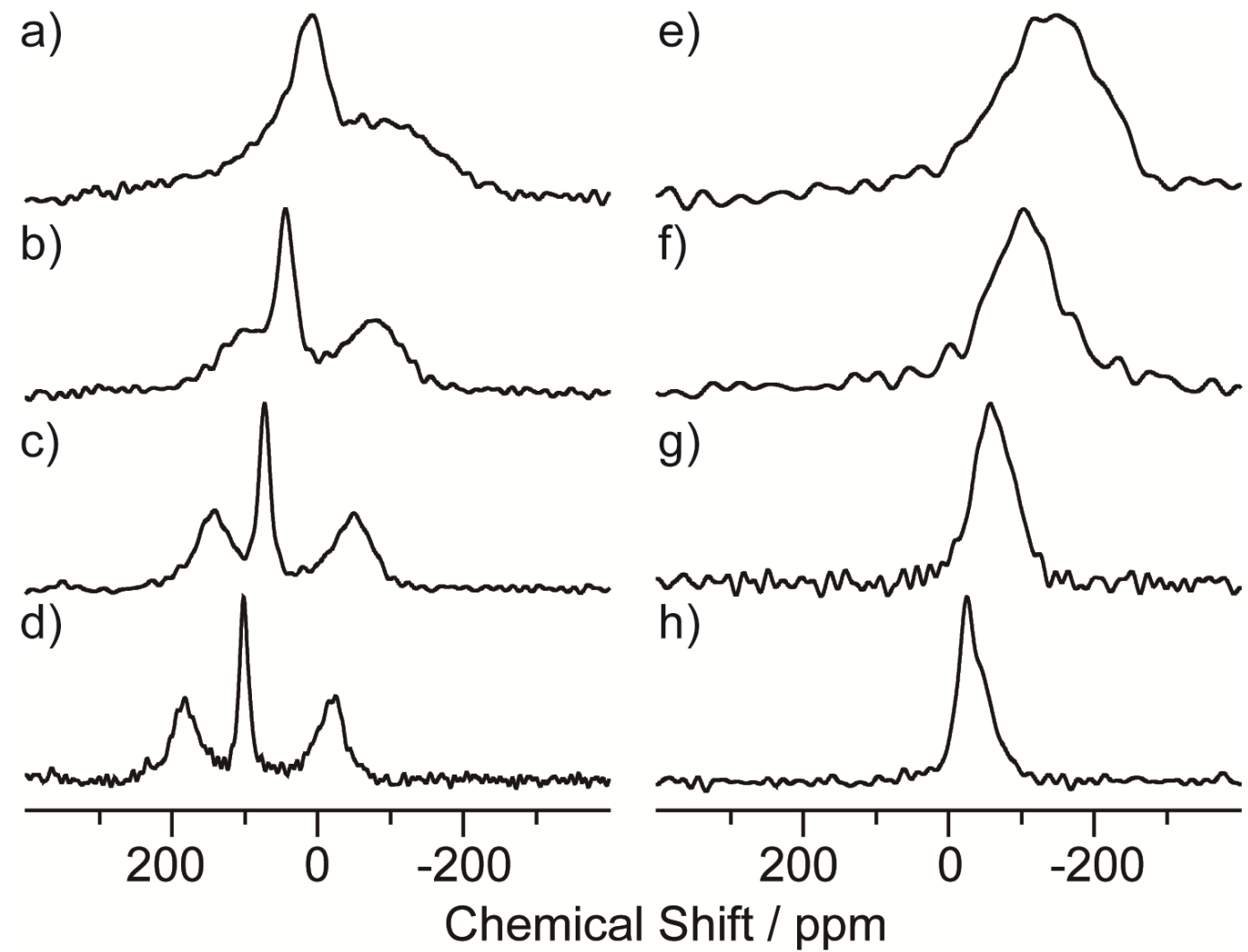

Figure 7. ${ }^{207} \mathrm{~Pb}$ MAS-NMR spectra of the $\beta^{+}(\mathrm{a}-\mathrm{d})$ and $\beta$ (e-h) samples observed at $-40{ }^{\circ} \mathrm{C}(\mathrm{a}, \mathrm{e}), 0{ }^{\circ} \mathrm{C}(\mathrm{b}, \mathrm{f}), 40{ }^{\circ} \mathrm{C}(\mathrm{c}, \mathrm{g})$, and $80{ }^{\circ} \mathrm{C}(\mathrm{d}, \mathrm{h})$. 


\section{Supporting Information}

\section{High Anionic Conductive Form of $\mathrm{Pb}_{x} \mathrm{Sn}_{2-x} \mathrm{~F}_{4}$}

Miwa Murakami ${ }^{\dagger, *}$, Yoshiyuki Morita ${ }^{\dagger}$, Masao Yonemura ${ }^{\ddagger}$, Keiji Shimoda ${ }^{\dagger}$, Masahiro Mori ${ }^{\dagger}$,

Yukinori Koyama ${ }^{\dagger}$, Tomoya Kawaguchi ${ }^{\dagger}$, Katsutoshi Fukuda ${ }^{\dagger}$, Yoshihisa Ishikawa ${ }^{\ddagger}$, Takashi Kamiyama $^{\ddagger}$, Yoshiharu Uchimoto ${ }^{\S}$, and Zempachi Ogumi ${ }^{\dagger}$

${ }^{\dagger}$ Office of Society-Academia Collaboration for Innovation, Kyoto University, Uji, Kyoto, 611-0011, Japan.

${ }^{\ddagger}$ High Energy Accelerator Research Organization, Tokai-mura, Naka-gun, Ibaraki 319-1106, Japan

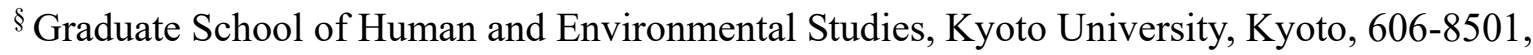
Japan.

*email m-murakami@saci.kyoto-u.ac.jp

Gokasho, Uji, Kyoto 611-0011, Japan

Tel: +81-774-38-4967, Fax: +81-774-38-4996

\section{Contents}

Figure S1. Observed (red cross) and calculated (blue line) neutron diffraction profile for $\beta^{+}-\mathrm{PbSnF}_{4}(x=1.15)$.

Figure S2. Figure S2. Temperature dependence of the ${ }^{207} \mathrm{~Pb}$ chemical shifts in $\beta^{+}$- and $\beta-\mathrm{PbSnF}_{4}$ obtained by spectral decomposition. 


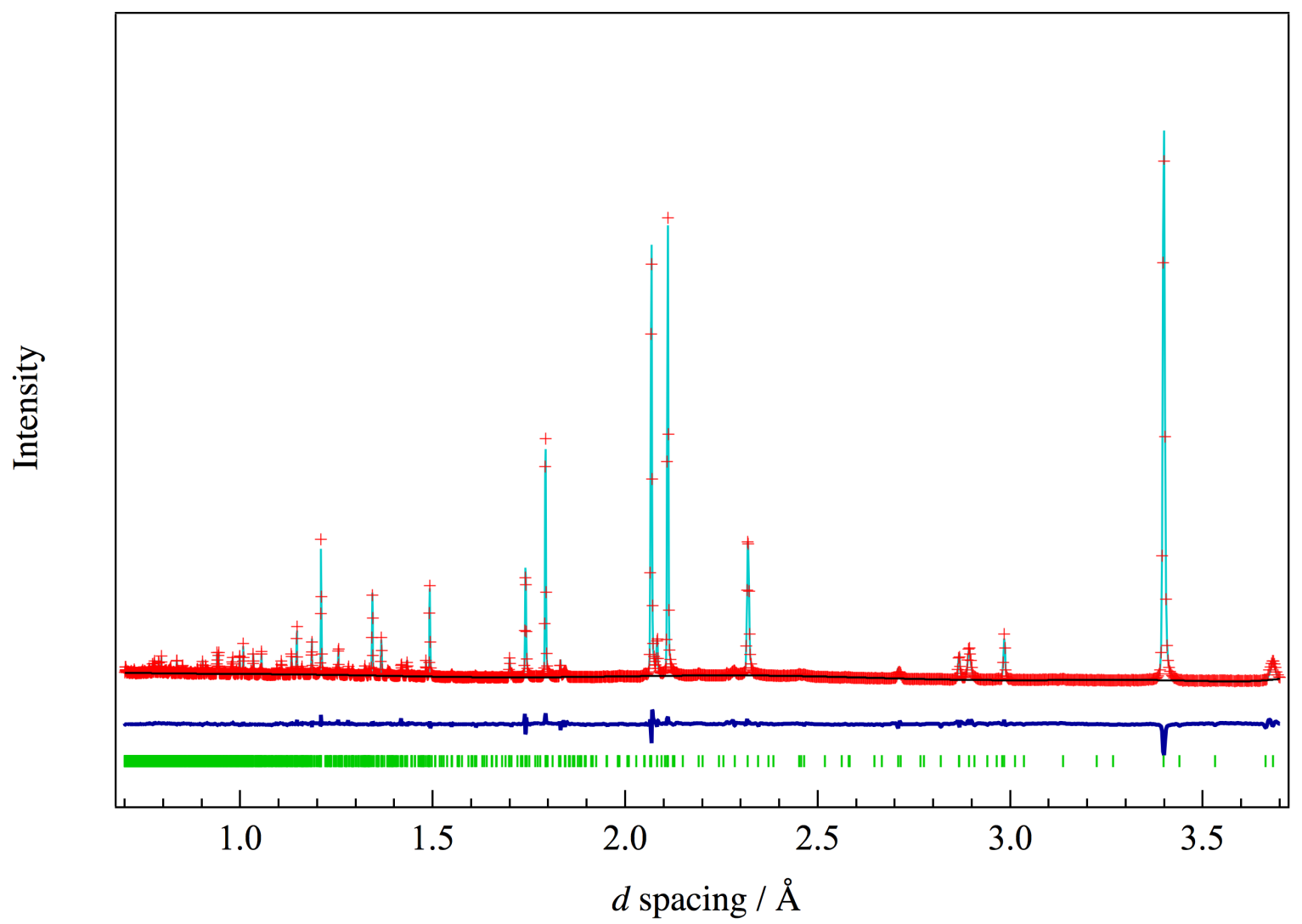

Figure S1. Observed (red cross) and calculated (blue line) neutron diffraction profile for $\beta^{+}-\mathrm{PbSnF}_{4}(x=1.15)$. A difference curve (observed minus calculated, blue line) is shown at the bottom of figure; under the diffraction profiles, reflection positions are indicated by green tick marks. The cell parameters are as follows: space group $P 4 / n m m, a=4.22030(3) \AA, c=51.59771(76) \AA$, volume $=919.0023(16) \AA^{3}$. 


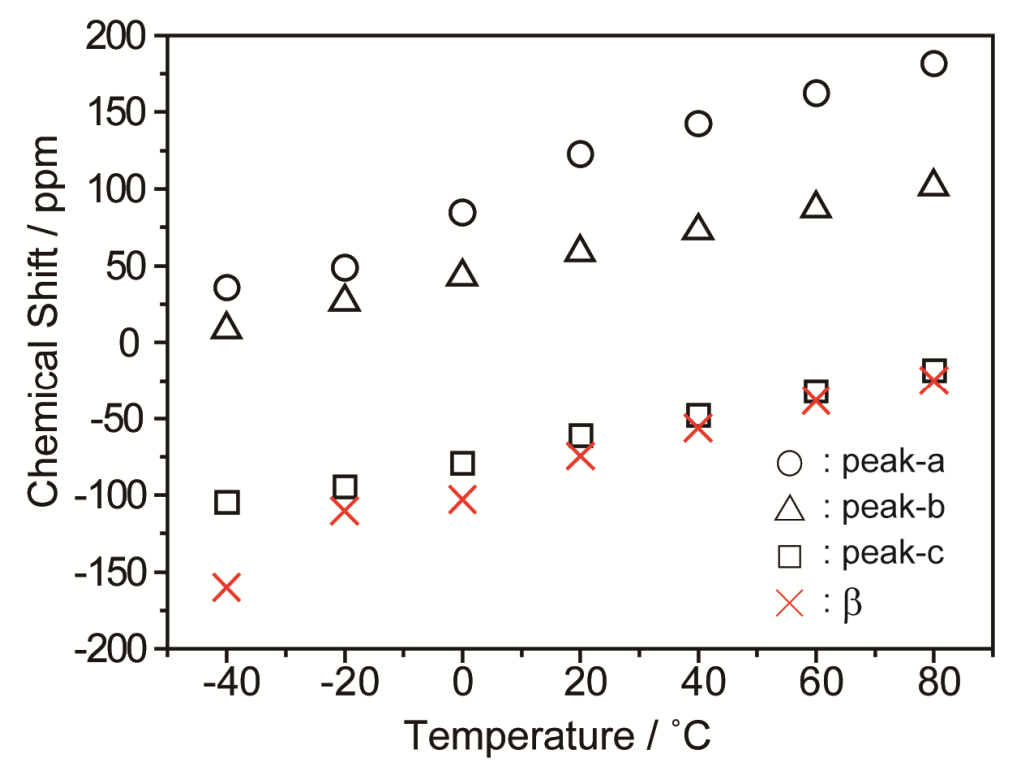

Figure S2. Temperature dependence of the ${ }^{207} \mathrm{~Pb}$ chemical shifts in $\beta^{+}$- and $\beta-\mathrm{PbSnF}_{4}$ obtained by spectral decomposition. 